\title{
PROGNOSTIC RELEVANCE OF RISK FACTORS FOR OBSTETRICAL BRACHIAL PLEXOPATHY
}

\author{
Carlos O. Heise1, José Luiz D. Gherpelli²
}

\begin{abstract}
We did a case-control study to verify if the birthweight, forceps delivery or perinatal asphyxia have any significant effect on the prognosis of obstetrical brachial plexopathy. Group A was composed of 25 infants who completely re cove red at the age of 6 months. Group B was composed of 21 infants who were still not able to remove a blindfold from the face with the affected limb in the sitting position at the age of 12 months. There was no statistical difference of the median birthweight or median first minute Apgar score between the groups. There was also no relation between birthweight higher than $4000 \mathrm{~g}$, first minute Apgar score lower than 6 or forceps delivery with a poor prognosis.
\end{abstract}

KEY WORDS: brachial plexus, obstetric paralysis, risk factors, birth weight, obstetrical forceps, Apgar score.

\section{Relevância prognóstica dos fatores de risco para plexopatia braquial obstétrica}

RESUMO - Realizamos um estudo caso-controle para verificar se o peso ao nascimento, parto forceps ou asfixia perinatal apresentam efeito significativo no prognóstico da plexopatia braquial obstétrica. 0 grupo A foi composto por 25 lactentes que apresentavam recuperação completa aos 6 meses de idade. 0 grupo $B$ foi composto por 21 lactentes incapazes de remover uma venda do rosto com o membro acometido na posição sentada aos 12 meses de idade. Não houve diferença significativa entre as medianas de peso ao nascimento ou do boletim Apgar do primeiro minuto entre os grupos. Também não foi observadarelação entrepeso ao nascimento maior que $4000 \mathrm{~g}$, boletim Apgar do primeiro minuto menor do que 6 ou part o forceps com um prognóstico desfavorável.

PALAVRAS-CHAVE: plexo braquial, paralisia obstétrica, fatores de risco, peso ao nascimento, forceps obstétrico, escore de Apgar.

Obstetrical brachial plexopathy (OBP) still is a common consequence of birth trauma. Its incidence in developed countries is around $0.15 \% \%^{1,2}$ and has not been reduced despite pro g ress in obstetrics ${ }^{2,3}$. Fort unately, most patients with OBP will fully recover after a few months, but $5 \%$ to $25 \%$ of them will remain handicapped ${ }^{2,4-8}$. The brachial plexus is formed by the anterior branch of the spinal roots from $\mathrm{C} 5$ to $\mathrm{T} 1^{9}$. Supraclavicular plexus lesions, such as OBP, can be clinically and anatomically divided into superior (C5C6), middle (C7) and inferior (C8-T1) levels ${ }^{10}$. Pure upper level plexopathy, or Erb palsy, accounts for $50 \%$ of the cases ${ }^{11}$. These patients have poor elbow flexion, shoulder abduction, arm external rotation, and fore a rm supination ${ }^{12}$. The wrist extension may also be weak due to the involvement of the extensor carpi radialis muscles. The resulting posture is classically described as "waiter's tip"11. One third of the patients with OBP have an upper and middle levels plexopathy. Middle level plexus involvement leads to poor elbow, wrist, and fingers extension ${ }^{12}$. Pure lower level plexopathy, or Klumpke palsy, is extremely rare ${ }^{11}$. These patients have poor fingers flexion and thumb opposition, and may also exhibit a Horner syn$\mathrm{d}$ rome (miosis, ptosis, enophthalmos and anhydrosis). One sixth of the patients with OBP have a complete brachial plexus lesion (from C5 to T1) and show a total limb paralysis (flail arm), with or without Horner syndrome ${ }^{10}$.

Several risk factors for OBP have been identified, the most well know being high birthweight and assisted delivery ${ }^{1,2,4,13,14}$. Perinatal asphyxia may also be a contributing factor, because the associated hypotonia would make the fetus more vulnerable to stretch injuries ${ }^{10,15}$. Although the relation of these factors with the occurrence of OBP has been established, their effect on neurological prognosis is uncertain. Ambulatório de Neurologia do Desenvolvimento da Clínica Neurológica do Hospital das Clínicas da Faculdade de Medicina da
Universidade de São Paulo, São Paulo SP, Brazil: ${ }^{1} \mathrm{MD}$; MSc; ${ }^{2} \mathrm{MD}$, PhD.

Received 25 May 2005, received in final form 5 August 2005. Accepted 30 September 2005.

Dr. Carlos O. Heise - Avenida Lacerda Franco 220 - 01536-000 São Paulo SP - Brasil. E-mail: carlos.heise@fleury.com.br 
The objective of this study was to verify if these risk factors have prognostic relevance or not.

\section{METHOD}

F rom July 2000 to December 2004, 79 infants with OBP (0-10 months old) were referred to the child neurology outpatient unit of the Clinics Hospital of Sao Paulo. We did a case-control study based on two groups selected from these children. The research ethical committee of the hospital approved this study.

G roup A (good prognosis) was composed of 25 infants who showed complete recoveryand no strength asymmetry at the age of 6 months. There were 21 patients with C5C6 palsy; 3 patients with $\mathrm{C} 5-\mathrm{C} 6-\mathrm{C} 7$ palsy, and one patient with C8-T1 palsy. All patients were admitted before 60 days of age (median=16 days). The follow-up of these children was at least 4 months long (range: $4-12$ months; median $=6$ months).

Group B (poor prognosis) was composed of 21 infants who still were unable to remove a blindfold from the face with the affected limb in the sitting position at the age of 12 months. There were 10 patients with complete brachial plexus paralysis (C5-T1); 10 patients with $\mathrm{C} 5-\mathrm{C} 6-\mathrm{C} 7$ palsy (one of them bilateral), and one patient with C5-C6 palsy. Twelve patients were admitted before 60 days of age (median=28 days), and nine patients were re fe rred later for surgery, at the age of 3 to 10 months (median= 8 months). The follow-up of these children ranged from 2 to 52 months (median=32 months). Seventeen patients from this group we refollowed-up until at least two years of age and none of them developed good arm function. Five of these children were submitted to brachial plexus neurolysis before the age of 12 months, but there was no strength loss after the surgeny. Therefore, the poor outcome could not be attributed to the surgical procedure.

The patients excluded from the study had an incomplete follow-up $(n=18)$, intermediate outcome $(n=9)$, cerebral palsy $(n=3)$, or were submitted to brachial plexus surgery with nerve grafts $(n=3)$. Patients submitted to surgery with nerve grafts can lose muscle power after the surgery because the nerves are sectioned in order to place the grafts. Patients with intermediate outcome were able to remove the blindfold from the face with the affected limb at 12 months of age, but still had clear strength asymme- try (usually for supination and arm external rotation) or scapular winging.

We compared the two groups in relation to birthweight, first minute Apgar score (FMAS) and mode of delivery. FMAS was employed in order to evaluate the possible role of fetal hypotonia secondary to birth asphyxia during delive ry and not the eventual hypoxic-ischemic encephalopathy. Data on birthweight and delivery mode were available in all patients. The FMAS was available in 24 patients of group A and 17 patients of group B. We used the ANOVA test to compare mean birthweight and Kruskal-Wallis test for median FMAS. Birthweight and FMAS were also transfo rmed in categorical variables to calculate the odds ratios. The patients exposed to risk factors should have birthweight higher than $4000 \mathrm{~g}$, FMAS of less than 6 and forceps delive ry. The confidence intervals for odds ratios were calculated using $95 \%$ exact confidence limits. Statistic analysis was done using the Epi Info 2002 program (CDC, Atlanta, USA).

\section{RESULTS}

In group A, birthweight ranged from $2570 \mathrm{~g}$ to $4450 \mathrm{~g}$ (Fig 1). The median birthweight is shown in Table 1. Eight patients weighted more than $4000 \mathrm{~g}$ (Table 2). There were two pre - t e rmand 23 full-term infants. Eleven infants were large-for-gestational age, and 14 were adequate-for-gestational age. In group $\mathrm{B}$, birthweight ranged from $2000 \mathrm{~g}$ to $5515 \mathrm{~g}$ (Fig 1). The median weight is shown in Table 1 . There were 9 patients who weighted above $4000 \mathrm{~g}$ (Table 2). All infants were full-term. Nine infants were large-forgestational age, one patient was small-for-gestational age, and 11 had adequate-for-gestational age.

Table 1. Differences of medians of birthweight and first minute Apgar scores between the two groups.

\begin{tabular}{lccc}
\hline Parameter & Group A* & Group B $^{\dagger}$ & p value \\
\hline Birthweight & $3,780 \mathrm{~g}$ & $3,950 \mathrm{~g}$ & 0.16 \\
$1^{\text {st }}$ min Apgar score & 6 & 5 & 0.19 \\
\hline
\end{tabular}

${ }^{*}$ Good prognosis group; ${ }^{+}$Poor prognosis group.

Table 2. Proportion of patients exposed to the risk factors in the two groups, and odds ratio and confidence interval for a poor prognosis based on the presence of the risk factors.

\begin{tabular}{lcccc}
\hline Risk factor & Group A* & Group B $^{\dagger}$ & Odds Ratio $^{*}$ & C.I. $^{\ddagger}$ \\
\hline Birthweight $>4 \mathrm{Kg}$ & $32 \%$ & $43 \%$ & 1.59 & $0.41-6.30$ \\
$1^{\text {st }}$ Apgar score $<6$ & $46 \%$ & $53 \%$ & 1.33 & $0.32-5.52$ \\
Forceps delivery & $36 \%$ & $24 \%$ & 0.56 & $0.12-2.38$ \\
\hline
\end{tabular}

*Good prognosis group; ${ }^{\dagger}$ Poor prognosis group; ${ }^{\ddagger} 95 \%$ confidence interval. 


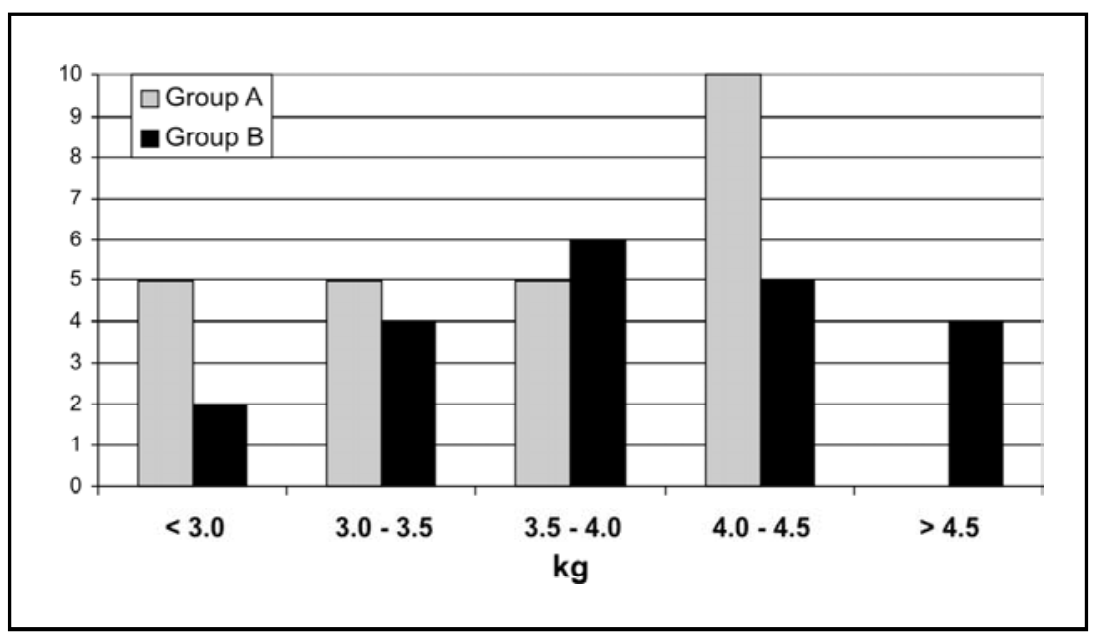

Fig 1. Birthweight histogram of the infants of both groups.

Fig 2. First minute Apgar score histogram of the infants of both groups.
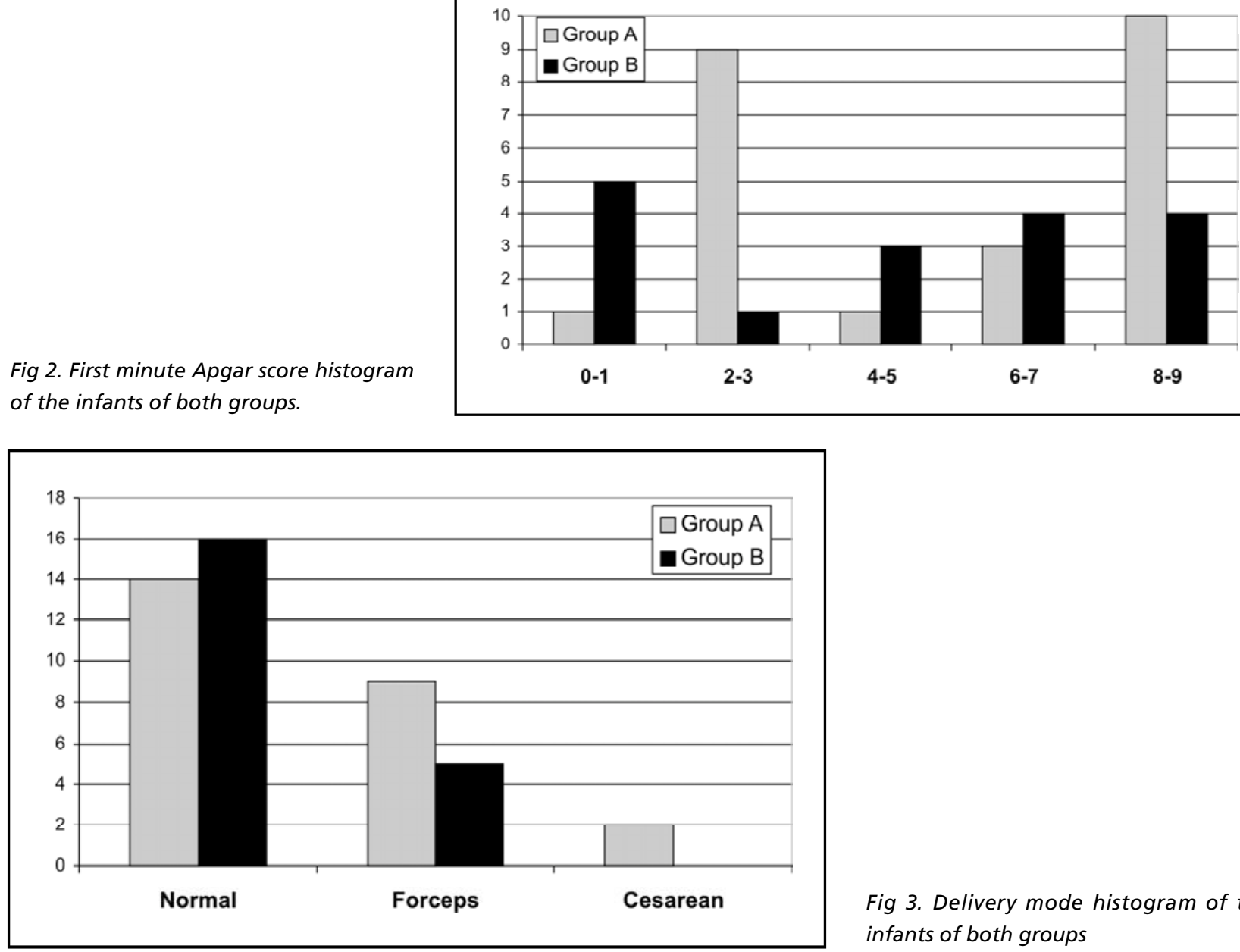

Fig 3. Delivery mode histogram of the infants of both groups

There was no statistically significant difference of birthweight between the groups.

In the group A, the FMAS ranged from 1 to 9 (Fig 2). The median FMAS is shown in Table 1. There were 11 patients with a FMAS below 6 (Table 2). In the group B, the FMAS ranged from 0 to 8 (Fig 2). The median FMAS is shown in Table 1. There were 9 patients with a FMAS below 6 (Table 2). There was also no statistically significant diffe rence between the groups.

In the group A, there were 14 normal deliveries, 9 forceps deliveries, and 2 cesareans (Fig 3). In the group $B$, there were 16 normal deliveries and 5 forceps deliveries (Fig 3). There was no statistically significant difference between the groups (Table 2). 


\section{DISCUSSION}

We could not demonstrate any relation between birthweight, perinatal asphyxia or forceps delivery and neurological prognosis of infants with OBP. Patients with poor prognosis had slightly higher birt $h$ weight and slightly lower FMAS than patients with good prognosis, but this was not statistically significant. Surprisingly, patients with good prognosis had a higher proportion of forceps deliveries, but this was also not statistically significant.

There is a clear relation between the rate of recove ry and the final prognosis of patients with OBP. The ideal age to define the final outcome would be three years, because the patients are not expected to imp rove after this age ${ }^{16}$. However, Noetzel et al. could correctly predict the 18-24 months outcome of infants with OBP based on the neurological impairment at 6 month of age ${ }^{17}$ and Basheer et al. found that $90 \%$ of patients reach their final clinical status at 6 months of age ${ }^{18}$. Our criterion for poor prognosis relies on a functional test at the age of 12 months. This test was based on the "cookie test" employed by Clarke and Curtis at the age of nine months as a criterion for surgical intervention ${ }^{19}$. It has the advantage of being objective and easily performed. All children from the "good prognosis" group were able to perform this test at 6-7 months of age.

Our study may not have enough power to detect the prognostic effect of birthweight and FMAS due to the small sample size. Larger studies or meta-analysis could possibly answer this question with more certitude. However, OBP is not a common condition and large series are difficult to provide. Meta-analysis is almost impossible since the follow-up period, the assessment protocol and the definitions of "good" and "poor" prognosis are so different among the publications dealing with OBP prognosis that the data cannot be compared ${ }^{16}$.

High birthweight is a very important risk factor for $\mathrm{OBP}^{1,2}$, but the effect of birthweight on the prognosis of affected newborns is controversial. Nehme et al. did a retrospective study with 30 patients and found that high birthweight was associated with poor prognosis in a multivariate analysis when associated with the neurological involvement ${ }^{20}$. Bager, in a prospective cohort study with 41 patients, could not find any association between birthweight and the neurological outcome².

Assisted deliveries, including forceps and ventouse, carry a higher risk for $\mathrm{OBP}^{1}$. Vacuum extraction assisted deliveries are not usually performed in our coun- try. Although forceps delivery is clearly associated with an increased risk of $\mathrm{OBP}^{14}$, Brown believes that the forceps has no causal relation and that it is only another consequence of a difficult delivery ${ }^{21}$.

Evans-Jones et al. did a large study based on active surveillance for OBP in the United Kingdom and Ireland ${ }^{3}$. The outcome assessment was based on 322 questionnairessent to consultant pediatricians, from which 276 questionnaires returned. The assessment was done at the age of 23 weeks (range 18-27). There were $52 \%$ cases with full re c o v e ry, $46 \%$ with part i a I recovery, and $2 \%$ with no recoveryat that age. They did not find a higher rate of incomplete recovery for macrosomic infants (relative risk: 1.37; confidence interval: $0.91-2.04$ ) or patients with assisted deliveries (relative risk: 0.93; confidence interval: 0.72-1.22).

We are not aware of any study that specifically addresses the effect of FMAS on the prognosis of infants with OBP. Perinatal asphyxia is frequently associated with $\mathrm{OBP}^{4,7,14}$. The theory that hypotonia induced by perinatal hypoxia predisposes the fetus to a brachial plexus stretch injury seems logical ${ }^{15}$, but lacks experimental confirmation. Furthermore, the asphyxia should occur prior to the brachial plexus lesion, which is impossible to be sure in this study. Fetal blood $\mathrm{pH}$ is a better instrument than Apgar score to measure fetal hypoxia ${ }^{22}$.

In summary, the prognosis of OBP cannot rely on factors such as birthweight, delivery mode or perinatal asphyxia. Nerve conduction studies may be helpful for prognostic assessment ${ }^{23}$, but the best prognostic guides still are the neurological impairment and the rate of recovery ${ }^{17,19,24}$.

\section{REFERENCES}

1. Gilbert WM, Nesbitt TS, Danielsen B. Associated factors in 1611 cases of brachial plexus injury. Obstet Gynecol 1999;93:536-540.

2. Bager B. Perinatally acquired brachial plexus palsy: a persisting challenge. Acta Paediatr 1997;86:1214-1219.

3. Evans-Jones G, Kay SPJ, Weindling AM, et al. Congenital brachial palsy: incidence, causes, and outcome in the United Kingdom and Republic of Ireland. Arch Dis Child Neonatal Ed 2003;88:F185-F189.

4. Gordon M, Rich H, Deutschberger J, Green M. The immediate and longterm outcome of obstetric birth trauma: I. Brachial plexus paralysis. Am J Obstet Gynecol 1973;117:51-56.

5. Greenwald AG, Schute PC, Shiveley JL. Brachial plexus birth palsy: a 10-year report on the incidence and prognosis. J Pediatr Orthop 1984;4: 689-692.

6. Sjöberg I, Erichs K, Bjerre I. Cause and effect of obstetric (neonatal) brachial plexus palsy. Acta Paediatr Scand 1988;77:357-364.

7. Hardy AE. Birth injuries of the brachial plexus: incidence and prognosis. J Bone Joint Surg Br 1981;63:98-101.

8. Sundholm LK, Eliasson, AC, Forssberg H. Obstetric brachial plexus injuries: assessment protocol and functional outcome at age 5 years. Dev Med Child Neurol 1998;40:4-11. 
9. Ferrante MA, Wilbourn AJ. Electrodiagnostic approach to the patients with suspected brachial plexopathy. Neurol Clin N Am 2002;20:423450.

10. Painter MJ, Bergman I. Obstetric trauma of the neonatal central and peripheral nervous system. Semin Perinatol 1982;6:89-104.

11. Van Dijk JG, Pondaag W, Malessy MJA. Obstetric lesions of the brachial plexus. Muscle Nerve 2001;24:1451-1461.

12. Alfonso I, Alfonso DT, Papazian O. Focal upper extremity neuropathy in neonates. Semin Pediatr Neurol 2000;7:4-14.

13. Donnelly V, Foran A, Murphy J, McParland P, Keane D, O'Herlihy C. Neonatal brachial plexus palsy: an unpredictable injury. Am J Obstet Gynecol 2002;187:1209-1212.

14. McFarland LV, Raskin M, Daling JR, Benedetti TJ. Erb/Duchenne's palsy: a consequence of fetal macrosomia and method of delivery. Obstet Gynecol 1986;68:784-788.

15. Server JW. Obstetric paralysis: report of eleven hundred cases. JAMA 1925;85:1862-1865.

16. Pondaag W, Malessy MJA, Van Dijk JG, Thomeer RTWM. Natural history of obstetric brachial plexus palsy: a systematic review. Dev Med Child Neurol 2004;46:138-144
17. Noetzel MJ, Park TS, Robinson S, Kaufman B. Prospective study of recovery following neonatal brachial plexus injury. J Child Neurol 2001; 16:488-492.

18. Basheer H, Zelic V, Rabia F. Functional scoring system for obstetric brachial plexus palsy. J Hand Surg Br 2000;25:41-45.

19. Clarke HM, Curtis CG. An approach to obstetrical brachial plexus injuries. Hand Clin 1995;4:563-581.

20. Nehme A, Kany J, Sales-De-Gauzy J, Dautel G, Cahuzac JP. Obstetrical brachial plexus palsy: prediction of outcome in upper root injuries. J Hand Surg Br 2002;27:9-12.

21. Brown KLB. Review of obstetrical palsies: nonoperative treatment. Clin Plast Surg 1984;11:181-187.

22. Marrin M, Paes BA. Birth asphyxia: does the Apgar score have diagnostic value? Obstet Gynecol 1988;72:120-123.

23. Heise CO, Lorenzetti L, Marchese AJT, Gherpelli JLD. Motor conduction studies for prognostic assessment of obstetrical plexopathy. Muscle Nerve 2004;30:451-455

24. Waters PM. Comparison of the natural history, the outcome of microsurgical repair and the outcome of operative reconstruction in brachial plexus birth palsy. J Bone Joint Surg Am 1999;81:649-659. 